\title{
Zeolite-Templated Carbon Materials for High-Pressure Hydrogen Storage
}

Nicholas P. Stadie, ${ }^{* \dagger}$ John J. Vajo, ${ }^{\ddagger}$ Robert W. Cumberland, ${ }^{\ddagger}$ Andrew A. Wilson, ${ }^{\S}$ Channing C. Ahn, ${ }^{\dagger}$ and Brent Fultz ${ }^{\dagger}$

${ }^{\dagger}$ W.M. Keck Laboratory, California Institute of Technology, 138-78, Pasadena, California 91125, United States

${ }^{\ddagger}$ HRL Laboratories, LLC, Malibu, California 90265, United States

${ }^{\S}$ Cavendish Laboratory, University of Cambridge, Cambridge CB3 OHE, U.K.

\section{Supporting Information}

ABSTRACT: Zeolite-templated carbon (ZTC) materials were synthesized, characterized, and evaluated as potential hydrogen storage materials between 77 and $298 \mathrm{~K}$ up to $30 \mathrm{MPa}$. Successful synthesis of high template fidelity ZTCs was confirmed by X-ray diffraction and nitrogen adsorption at $77 \mathrm{~K}$; BET surface areas up to $\sim 3600 \mathrm{~m}^{2} \mathrm{~g}^{-1}$ were achieved. Equilibrium hydrogen adsorption capacity in ZTCs is higher than all other materials studied, including superactivated carbon MSC-30. The ZTCs showed a maximum in Gibbs surface excess uptake of $28.6 \mathrm{mmol} \mathrm{g}^{-1}(5.5 \mathrm{wt} \%)$ at $77 \mathrm{~K}$, with hydrogen uptake capacity at $300 \mathrm{~K}$ linearly proportional to BET surface area: $2.3 \mathrm{mmol} \mathrm{g}^{-1}(0.46 \mathrm{wt} \%)$ uptake per $1000 \mathrm{~m}^{2} \mathrm{~g}^{-1}$ at $30 \mathrm{MPa}$. This is the same trend as for other carbonaceous materials, implying that the nature of high-pressure adsorption in ZTCs is not unique despite their narrow microporosity and significantly lower skeletal densities. Isoexcess enthalpies

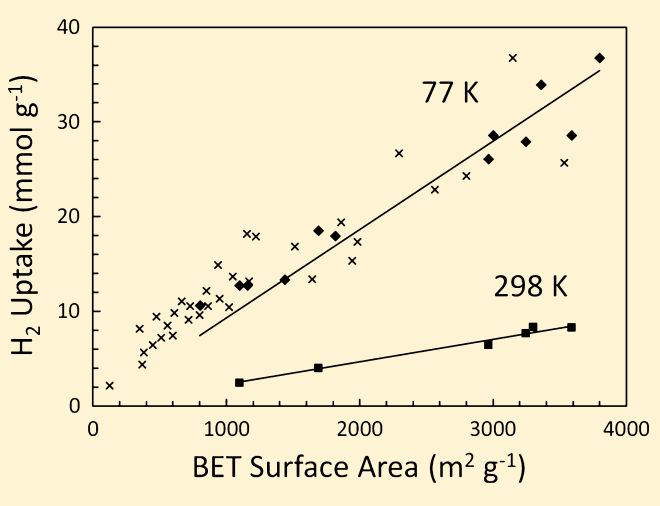
of adsorption are calculated between 77 and $298 \mathrm{~K}$ and found to be $6.5-6.6 \mathrm{~kJ} \mathrm{~mol}^{-1}$ in the Henry's law limit.

\section{INTRODUCTION}

Porous materials with high specific surface areas continue to attract widespread attention as candidate hydrogen storage materials due to their inherent reversibility, fast kinetics, and high cyclability during hydrogen adsorption. ${ }^{1,2}$ Carbonaceous sorbents are particularly attractive because they are lightweight, abundantly available, and simple to produce. ${ }^{3-5}$ Carbons with remarkably high surface areas (up to $\sim 3000 \mathrm{~m}^{2} \mathrm{~g}^{-1}$ ) can be made by conventional chemical activation, among other methods. However, weak hydrogen binding interactions (typically 4-6 kJ $\left(\mathrm{mol} \mathrm{H} \mathrm{H}_{2}\right)^{-1}$ ) limit their effective use to cryogenic temperatures, and it is predicted that an ideal heat of adsorption for effective storage near ambient conditions is $\sim 15$ $\mathrm{kJ} \mathrm{mol}^{-1}$. At $^{6} 7 \mathrm{~K}$, Gibbs's excess hydrogen uptake in carbon sorbents increases until a maximum value is reached, typically between 1 and $4 \mathrm{MPa}$; this value correlates linearly with the specific surface area of the material. A rule of thumb for carbon materials, "Chahine's rule", predicts $\sim 2$ wt \% excess uptake of hydrogen (when measured at $77 \mathrm{~K}$ and the Gibbs excess surface maximum pressure) per $1000 \mathrm{~m}^{2} \mathrm{~g}^{-1}$ of surface area, as measured with $\mathrm{N}_{2}$ in the BET method. ${ }^{3,4}$ This capacity is consistent with the theoretical value expected for hydrogen adsorbed in a $\sqrt{ } 3$ configuration on double-sided graphene sheets. Deviations from this trend are usually explained by increased or decreased surface binding interactions for a given surface chemistry or pore character or by inaccuracies in measurement techniques. ${ }^{7}$
Significant hydrogen sorption capacity at or near room temperature is an important target for candidate storage materials, and numerous strategies to enhance adsorption in carbons have been proposed (e.g., "spillover", ${ }^{8-11}$ light-atom doping, ${ }^{12,13}$ etc.), but none has yet proven to be a viable technology. Since adsorption of hydrogen at room temperature is very weak, excess uptake in physisorbent materials at modest pressures $(<10 \mathrm{MPa})$ is usually below 1 wt $\%$. There is no general rule relating specific surface area to excess hydrogen uptake capacity at $298 \mathrm{~K}$ because a Gibbs surface excess maximum is not achieved. However, hydrogen uptake at a given pressure is indeed known to be linearly correlated with specific surface area: $\sim 0.2$ wt $\%$ excess uptake of hydrogen per $1000 \mathrm{~m}^{2}$ $\mathrm{g}^{-1}$ at $6.5 \mathrm{MPa}^{4}$ for example, a factor of 10 lower than capacities at $77 \mathrm{~K}$.

Template carbonization, among other methods of structural control, has also been explored as a technique to produce carbonaceous materials with exceptionally large specific surface area and finely tuned porosity. ${ }^{14-20}$ It has been reported that a particular class of materials, zeolite-templated carbons (ZTCs), exhibits remarkable hydrogen storage capacities at room temperature under high-pressure conditions $(10-34 \mathrm{MPa}){ }^{16}$ This reported increase could not be explained by surface area alone; the uptake in ZTCs exceeded that of commercially

Received: December 14, 2011

Published: June 11, 2012 
available superactivated carbon of similar surface area, Maxsorb MSC-30, by nearly $100 \%$ at $34 \mathrm{MPa}$. Extremely narrow microporosity in ZTCs is credited with the improvement, exhibiting optimal pore size for the accommodation of two layers of hydrogen in each pore. ${ }^{17}$ However, heats of adsorption in ZTCs remain below $8 \mathrm{~kJ} \mathrm{~mol}^{-1}$, which is not consistent with this explanation. Additionally, BET surface area is notoriously susceptible to error in highly microporous materials such as ZTCs and may be a significant source of error in the characterization of uptake capacity per surface area at room temperature. Measurements of hydrogen adsorption in sorbent materials beyond $15 \mathrm{MPa}$ are few, and most tend toward a plateau beyond $10 \mathrm{MPa}$ at room temperature, while ZTCs are reported to continually increase in this high-pressure regime. ${ }^{16}$

In the present study, high surface area carbon sorbents were prepared by the zeolite-templating method; materials with BET surface areas of up to $3800 \mathrm{~m}^{2} \mathrm{~g}^{-1}$ were produced in multigram quantities. Hydrogen uptake measurements of these materials at 77,87 , and $298 \mathrm{~K}$ were performed with multiple instruments to assess the viability of ZTCs as hydrogen storage materials for room temperature applications. A specially designed volumetric apparatus was constructed and commissioned for measurements up to $70 \mathrm{MPa}$.

\section{EXPERIMENTAL METHODS}

2.1. Materials. Zeolum zeolite molecular sieve materials were obtained from Tosoh Corporation, specifically HSZ-320NAA (faujasite structure, $\mathrm{Na}$ cation, $\left.\mathrm{SiO}_{2} / \mathrm{Al}_{2} \mathrm{O}_{3}=5.5 \mathrm{~mol} / \mathrm{mol}\right)(\mathrm{NaY})$ and HSZ-930NHA (beta structure, $\mathrm{NH}_{4}$ cation, $\mathrm{SiO}_{2} / \mathrm{Al}_{2} \mathrm{O}_{3}=27 \mathrm{~mol} /$ mol) $(\mathrm{NH} \beta)$. Maxsorb MSC-30 superactivated carbon was obtained from Kansai Coke \& Chemicals Company, Ltd. Activated carbon CNS-201 was obtained from A. C. Carbons Canada Inc. These materials were stored at $150{ }^{\circ} \mathrm{C}$ under vacuum in a Buchi glass oven before use.

2.2. Synthesis. Zeolite-templated carbon (ZTC) materials were prepared at HRL and Caltech by previously established methods. ${ }^{16}$ At Caltech, dried zeolite $\left(<1\right.$ wt $\left.\% \mathrm{H}_{2} \mathrm{O}\right)$ and furfuryl alcohol $(98 \%$, Sigma-Aldrich) were combined at room temperature under reduced pressure. In the largest batches, $3 \mathrm{~g}$ of dried zeolite was added to 60 $\mathrm{mL}$ of furfuryl alcohol and magnetically stirred for $24 \mathrm{~h}$. The zeolitefurfuryl alcohol mixture was collected by vacuum filtration and washed with excess mesitylene (99.0\%, Sigma-Aldrich), yielding $3.5 \mathrm{~g}$ of a white-gray powder. The dry powder was transferred to ceramic boats and placed in $\mathrm{N}_{2}$ flow inside a horizontal alumina tube furnace, preheated to $80{ }^{\circ} \mathrm{C}$. Polymerization was performed under $\mathrm{N}_{2}$ flow at $150{ }^{\circ} \mathrm{C}$ for $12 \mathrm{~h}$. Temperature was increased at $2{ }^{\circ} \mathrm{C} \min ^{-1}$ to $700{ }^{\circ} \mathrm{C}$, and gas flow was then switched to a propylene $/ \mathrm{N}_{2}$ mixture $(7 \%$ propylene) for $2 \mathrm{~h}$. Gas flow was switched back to pure $\mathrm{N}_{2}$, and temperature was increased at $10{ }^{\circ} \mathrm{C} \mathrm{min}{ }^{-1}$ to $900{ }^{\circ} \mathrm{C}$. Carbonization at $900{ }^{\circ} \mathrm{C}$ was performed for $3 \mathrm{~h}$. The product, referred to as $\mathrm{Z}$-C, was cooled to room temperature and transferred to a PTFE beaker, yielding 2.5 g. A $3 \mathrm{~mL}$ aqueous solution of HF (48\%, EM Industries) was added dropwise to the Z-C, stirred, and allowed to dissolve for 2 h. The aqueous solution was further diluted in a large flask to 1200 $\mathrm{mL}$. The remaining solid product, ZTC, was collected by vacuum filtration and washed with water. The ZTC was dried and stored at $150{ }^{\circ} \mathrm{C}$ under vacuum in a Buchi glass oven. HF treatment was repeated until no zeolite peaks remained in the X-ray diffraction (XRD) pattern, yielding $1 \mathrm{~g}$ of final product. By this method, two different ZTC samples were prepared: ZTC-1 from zeolite $\mathrm{NH} \beta$ and ZTC-2 from zeolite NaY

At HRL, $6.0 \mathrm{~g}$ of zeolite $\mathrm{NaY}$ was further dried at $450{ }^{\circ} \mathrm{C}$ under vacuum for $8 \mathrm{~h}$ to $<0.02 \mathrm{wt} \% \mathrm{H}_{2} \mathrm{O}$. After cooling to room temperature, $12 \mathrm{~mL}$ of furfuryl alcohol (98\%, Sigma-Aldrich) was added by injection, and the mixture was stirred under an $\mathrm{Ar}$ atmosphere for $24 \mathrm{~h}$. The zeolite-furfuryl alcohol mixture was collected via vacuum filtration and washed 4 times with $100 \mathrm{~mL}$ aliquots of xylenes. The washed powder was placed in a $8 \times 8 \mathrm{~cm}$ shallow quartz boat and loaded into a $10 \mathrm{~cm}$ diameter quartz tube furnace/CVD reactor. The reactor was purged with $\mathrm{Ar}$ at room temperature and was held at $80{ }^{\circ} \mathrm{C}$ under Ar flow $\left(2 \mathrm{~L} \mathrm{~min}^{-1}\right)$ for $24 \mathrm{~h}$. Polymerization was performed at $150{ }^{\circ} \mathrm{C}$ under Ar flow $\left(2 \mathrm{~L} \mathrm{~min}^{-1}\right)$ for $8 \mathrm{~h}$. Temperature was increased at $5{ }^{\circ} \mathrm{C} \mathrm{min}{ }^{-1}$ to $700{ }^{\circ} \mathrm{C}$ under $\mathrm{Ar}$ flow $\left(2 \mathrm{~L} \mathrm{~min}^{-1}\right)$, and gas flow was then switched to a propylene $/ \mathrm{N}_{2}$ mixture (7\% propylene, $3.2 \mathrm{~L} \mathrm{~min}^{-1}$ ) for $4 \mathrm{~h}$. Holding the temperature at $700{ }^{\circ} \mathrm{C}$, the reactor was purged under Ar flow $\left(4 \mathrm{~L} \mathrm{~min}^{-1}\right)$ for 10 min. Temperature was increased to $900{ }^{\circ} \mathrm{C}$ under Ar flow $\left(2 \mathrm{~L} \mathrm{~min}^{-1}\right)$ and held for $3 \mathrm{~h}$. The NaY-C product was cooled to room temperature and transferred to a PTFE beaker where $200 \mathrm{~mL}$ of aqueous HF (48\%, Sigma-Aldrich) was added. After $16 \mathrm{~h}$, the ZTC was collected by vacuum filtration and washed 10 times with $50 \mathrm{~mL}$ aliquots of water. The ZTC was dried and stored at $150{ }^{\circ} \mathrm{C}$ under vacuum in a Buchi glass oven, yielding $1.4 \mathrm{~g}$ of final product. A TGA measurement conducted in air up to $1000{ }^{\circ} \mathrm{C}$ yielded a residual mass of $\sim 2 \%$, indicating nearly complete dissolution of the zeolite template. By this method, samples such as ZTC-3 were prepared.

By improving inert atmosphere conditions during combination of raw materials, polymerization, and carbonization, such as for ZTC-3, significant improvements in templating fidelity were observed. Careful control of inert atmosphere as well as thorough drying of the zeolite precursor was critical for obtaining a product with surface area beyond $3000 \mathrm{~m}^{2} \mathrm{~g}^{-1}$.

2.3. Characterization. Nitrogen isotherms were measured at $77 \mathrm{~K}$ with a BELSORP-max volumetric instrument (BEL-Japan Inc.), and surface areas were calculated using the BET method. ${ }^{21}$ Pore-size distributions were calculated by the nonlocal density functional theory (NLDFT) method ${ }^{22}$ from high-resolution data collected on a Micromeritics ASAP 2020, using a carbon slit pore model and software provided by Micromeritics. X-ray diffraction experiments were performed using a PANalytical X'Pert Pro powder diffractometer with $\mathrm{Cu} \mathrm{K} \alpha_{1,2}$ radiation.

2.4. Standard Hydrogen Uptake Measurements. Hydrogen adsorption isotherms at 77 and $87 \mathrm{~K}$ were measured with a custom volumetric Sieverts apparatus, commissioned, and verified for accurate measurements up to $10 \mathrm{MPa}{ }^{11,23,24}$ The apparatus was equipped with a digital cold cathode pressure sensor (I-MAG, Series 423), a highresolution pressure manometer (MKS Baratron, Model 120AA), a midrange (3000 psi) pressure manometer (MKS Baratron, Model 833 ), and a molecular drag pump to achieve a measurable pressure range of $10^{-5}-10^{7} \mathrm{~Pa}$. Temperature was measured on the wall of the manifold and on the outer wall of the sample holder using K-type thermocouples and platinum resistance thermometers (PRTs). Temperature baths of liquid nitrogen $(77 \mathrm{~K})$ and liquid helium $(87$ $\mathrm{K}$ ) were continually filled throughout experiments to maintain lowtemperature conditions in the sample cell if necessary. Gas densities were determined from temperature and pressure using the REFPROP Standard Reference Database. ${ }^{25}$ The system was leak tested up to 7 $\mathrm{MPa}$ and showed a maximum leak rate of $6.0 \times 10^{-7} \mathrm{~mol} \mathrm{~h}^{-1}$ of $\mathrm{H}_{2}$. If fitted to an exponential decay function, $n(t)=n_{0} \exp (-k t)$, where $k$ is the leak rate, this corresponds to a maximum leak of $k \sim 10^{-9} \mathrm{~s}^{-1}$, which is negligible for short time measurement. ${ }^{26}$ The total inner volume of the apparatus was $60 \mathrm{~mL}$. The true volume of the sample was subtracted from the empty volume of the sample holder using the skeletal density, measured by helium pycnometry. Hydrogen was exposed to the sample at incrementally higher pressures over the course of each isotherm in uniform equilibration steps, usually allowing 30-60 min between gas expansions to ensure thermal equilibration. The system was not returned to vacuum in between steps, and the measured hydrogen uptake was cumulative from step to step. Hydrogen uptake at each step was corrected for background adsorption of the instrument by subtracting the amount of perceived uptake at the same pressure in an empty sample holder.

2.5. High-Pressure Hydrogen Uptake Measurements. Hydrogen adsorption isotherms at $298 \mathrm{~K}$ were measured with a custom volumetric Sieverts apparatus designed to accommodate pressures up to $70 \mathrm{MPa}$. The apparatus was equipped with a Bayard-Alpert ionization vacuum gauge (Varian, 571), two 10000 psi pressure 
manometers (GE Druck, PDCR-4000), and a molecular drag pump to achieve a measurable pressure range of $10^{-5}-10^{8} \mathrm{~Pa}$. Temperature was measured inside the manifold and on the outer wall of the tubing using K-type thermocouples and silicon diode thermometers, respectively. High pressures were achieved by gas densification in a coil submerged in a liquid nitrogen bath and then removed and restored to ambient temperature. The total inner volume of the apparatus was $15 \mathrm{~mL}$, designed to maximize the measurement resolution for samples of 0.2$0.3 \mathrm{~g}$ in mass. ${ }^{27}$ Gas densities, sample density, and hydrogen uptake were determined as in section 2.4. The system was leak tested up to 45 $\mathrm{MPa}$ and showed a maximum leak rate of $2.2 \times 10^{-7} \mathrm{~mol} \mathrm{~h}^{-1}$ of $\mathrm{H}_{2}$. If fitted to an exponential decay function, $n(t)=n_{0} \exp (-k t)$ where $k$ is the leak rate, this corresponds to a maximum leak of $k \sim 10^{-8} \mathrm{~s}^{-1}$. Details of the design and construction of this apparatus will be reported elsewhere.

\section{RESULTS}

3.1. Materials Characterization. Diffraction patterns of ZTC-2 and ZTC-3 are shown in Figure 1, compared to the

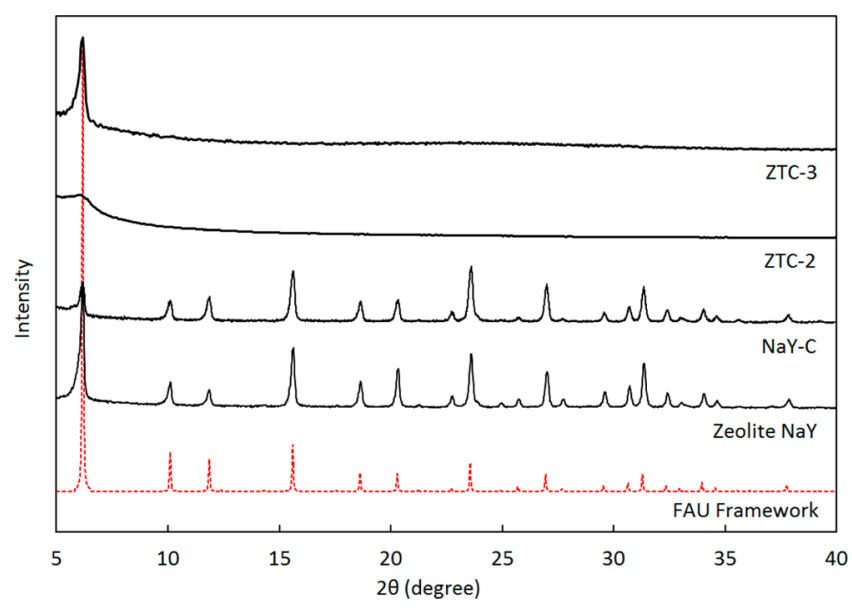

Figure 1. XRD patterns of final products ZTC-2 and ZTC-3, a composite zeolite-carbon intermediate product $(\mathrm{NaY}-\mathrm{C})$, pure zeolite $\mathrm{NaY}$ (as received), and the FAU zeolitic framework (calculated).

pure zeolite $\mathrm{NaY}$ precursor and the composite $\mathrm{NaY}-\mathrm{C}$ material before HF treatment. Also shown is the calculated crystal structure of the faujasite (FAU) framework. The sharp peak centered at $2 \theta=6^{\circ}$ is the (111) reflection of the cubic zeolite structure. In the final products, ZTC-2 and ZTC-3, no zeolite peaks were detected except this longest periodicity corresponding to the channel-to-channel structure of the template (14 $)$, suggesting complete removal of the template from the sample; the remaining peak verifies successful templating of the zeolitic framework in the ZTC. From the width of this diffraction peak, the length scale of the zeolitic order was calculated with the Scherrer equation to be $24 \mathrm{~nm}$ (using the Scherrer constant $K$ $=0.83$ for spherical particles) for ZTC-3. ${ }^{28}$

Equilibrium adsorption isotherms of $\mathrm{N}_{2}$ at $77 \mathrm{~K}$ are shown in Figure 2. Pore-size distributions of ZTC-3 and MSC-30 calculated by the DFT method are shown in Figure 3. Distinct regularity of pore size, centered at a width of $1.5 \mathrm{~nm}$, can be seen for ZTC-3, which is consistent with other reports. ${ }^{16}$ MSC30 shows a broader and larger pore size distribution. The BET surface areas of the materials studied are summarized in Table 1. Dubinin-Radushkevich (DR) micropore volume was also analyzed for all materials (see Supporting Information). Standard materials MSC-30 and CNS-201 were measured to have 3240 and $1100 \mathrm{~m}^{2} \mathrm{~g}^{-1}$ BET surface areas, respectively.

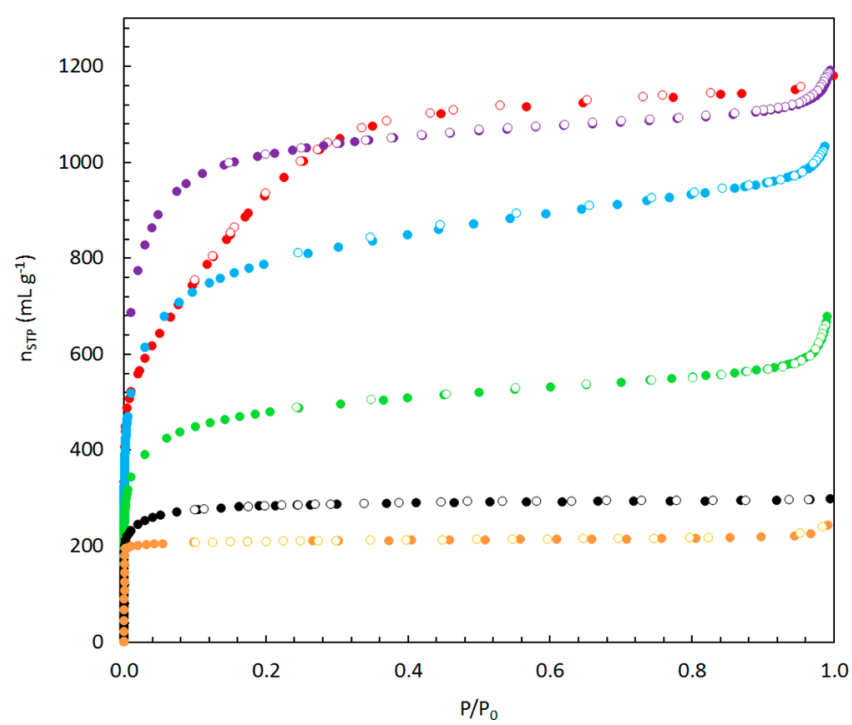

Figure 2. Equilibrium adsorption (closed) and desorption (open) isotherms of $\mathrm{N}_{2}$ at $77 \mathrm{~K}$ on MSC-30 (red), ZTC-1 (green), ZTC-2 (blue), ZTC-3 (purple), CNS-201 (black), and zeolite NaY (orange). Uptake is expressed in units of volume of $\mathrm{N}_{2}$ (at STP) per unit mass.

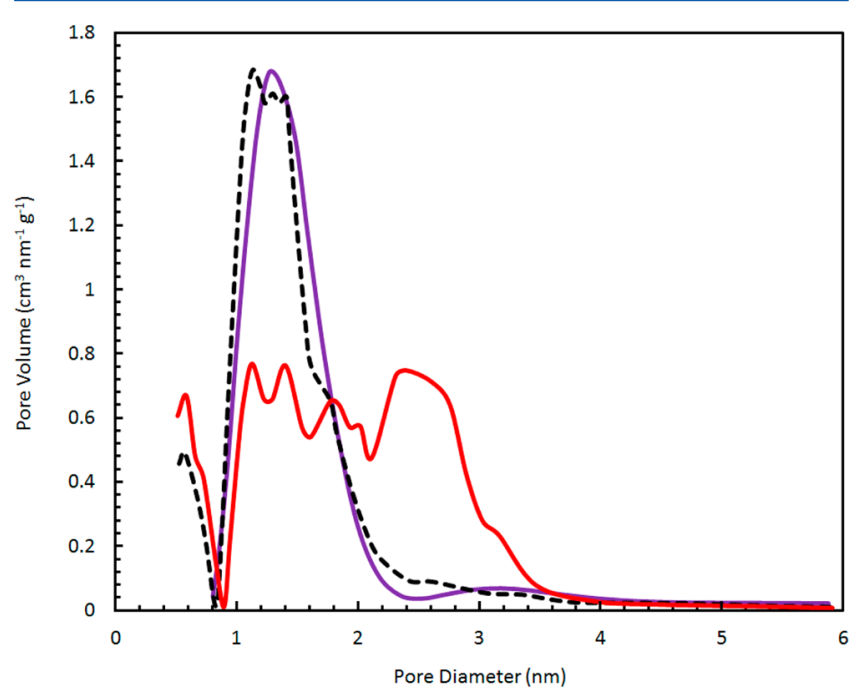

Figure 3. DFT pore-size distribution of ZTC-3 (purple) compared to MSC-30 (red) and ZTC "P7(2)-H" (dashed black), an equivalent reference material. ${ }^{16}$

BET surface area was calculated in the region up to "point $B$ ", where $B$ is the pressure corresponding to the start of the linear region in a type II isotherm curve. ${ }^{21}$ The BET surface area of MSC-30 was calculated in the region $0.0005<P / P_{0}<0.35$. Although the isotherm has some type IV character, it was treated as type II with "point B" at the start of the second linear region corresponding to $P / P_{0}=0.22$. Variation of the location of "point $\mathrm{B}$ " in this nontype II $\mathrm{N}_{2}$ isotherm introduces a difference of $\pm 400 \mathrm{~m}^{2} \mathrm{~g}^{-1}$. Evidently, the region of calculation for the specific surface area of MSC-30 is of crucial importance. The BET surface area of CNS-201 was calculated in the region $0.001<P / P_{0}<0.15$. Nitrogen uptake curves for all ZTC samples were type II, and the BET surface area was calculated in the region $0.01<P / P_{0}<B$. It is necessary to determine this pressure range separately for every material since the position of the knee in the isotherm is different for each. All materials measured show high BET surface area and high relative uptake 
Table 1. BET Surface Area (SA) and Hydrogen Uptake Capacity Reported for Carbonaceous Sorbent Materials: CNS-201, MSC-30, and ZTCs

\begin{tabular}{|c|c|c|c|c|c|}
\hline material & $\operatorname{density}^{b}\left(\mathrm{~g} \mathrm{~mL}^{-1}\right)$ & BET SA $\left(\mathrm{m}^{2} \mathrm{~g}^{-1}\right)$ & $\mathrm{H}_{2}$ capacity $^{c}\left(\mathrm{mmol} \mathrm{g}^{-1}\right)$ & high $P \mathrm{H}_{2}$ uptake $^{d}\left(\mathrm{mmol} \mathrm{g}^{-1}\right)$ & $\Delta H_{0}\left(\mathrm{~kJ} \mathrm{~mol}{ }^{-1}\right)$ \\
\hline CNS-201 ${ }^{a}$ & 2.1 & $1095 \pm 8$ & 12.7 & 2.48 & 8.6 \\
\hline $\operatorname{MSC}-30^{a}$ & 2.1 & $3244 \pm 28$ & 27.9 & 7.66 & 6.7 \\
\hline $\mathrm{ZTC} 1^{a}$ & 1.9 & $1691 \pm 21$ & 18.5 & 3.99 & \\
\hline ZTC-2 ${ }^{a}$ & 1.9 & $2964 \pm 18$ & 26.1 & 6.45 & 6.6 \\
\hline $\mathrm{ZTC}^{-} 3^{a}$ & 1.8 & $3591 \pm 60$ & 28.6 & 8.27 & 6.5 \\
\hline CNS- $201^{5}$ & 2.2 & 1440 & 12.9 & & \\
\hline MSC- $30^{5}$ & 2.2 & 3000 & 26.5 & & \\
\hline MSC- $30^{16}$ & 2.1 & 2680 & & 5.5 & 7.3 \\
\hline $\mathrm{P} 7(2)-\mathrm{H}^{16}$ & 1.9 & 3800 & & 10.7 & 8 \\
\hline
\end{tabular}

${ }^{a}$ From this study. ${ }^{b}$ Skeletal density measured using He at $300 \mathrm{~K}$ between 0 and $3 \mathrm{MPa} .{ }^{c}$ Measured using $\mathrm{H}_{2}$ at $77 \mathrm{~K}$ and Gibbs excess surface maximum pressure. ${ }^{d}$ Measured using $\mathrm{H}_{2}$ at $296-303 \mathrm{~K}$ and $30 \mathrm{MPa}$.

of $\mathrm{N}_{2}$ in the linear region of the isotherm, among the highest known for carbonaceous materials.

The skeletal densities of the materials studied are summarized in Table 1 , averaged over $>10$ helium pycnometry measurements per sample and performed between 0 and $3 \mathrm{MPa}$ and $298 \mathrm{~K}$. ZTC-1 and ZTC-2 were measured to be $1.9 \mathrm{~g} \mathrm{~mL}^{-1}$, while ZTC-3 was measured to be $1.8 \mathrm{~g} \mathrm{~mL}^{-1}$, a significant difference from the activated carbons studied (both $2.1 \mathrm{~g}$ $\mathrm{mL}^{-1}$ ); the standard error was $\pm 0.06 \mathrm{~g} \mathrm{~mL}^{-1}$ between samples. Previous measurements of carbon materials in our laboratory gave values of $2.12 \pm 0.05 \mathrm{~g} \mathrm{~mL}^{-1}$ over four different carbon types, including MSC-30. The significantly lower skeletal densities in ZTCs result in $\sim 1 \mathrm{mmol} \mathrm{g}^{-1}$ difference in the calculated excess hydrogen uptake at $30 \mathrm{MPa}$ and $298 \mathrm{~K}$. This is a significant change that must be taken into account for accurate uptake calculations.

3.2. Hydrogen Uptake Isotherms. Hydrogen uptake isotherms were measured for the ZTCs, and the standard materials MSC-30 and CNS-201, at 77, 87, and $298 \mathrm{~K}$. They are shown in Figure 4. Hydrogen adsorption is reported as Gibbs's

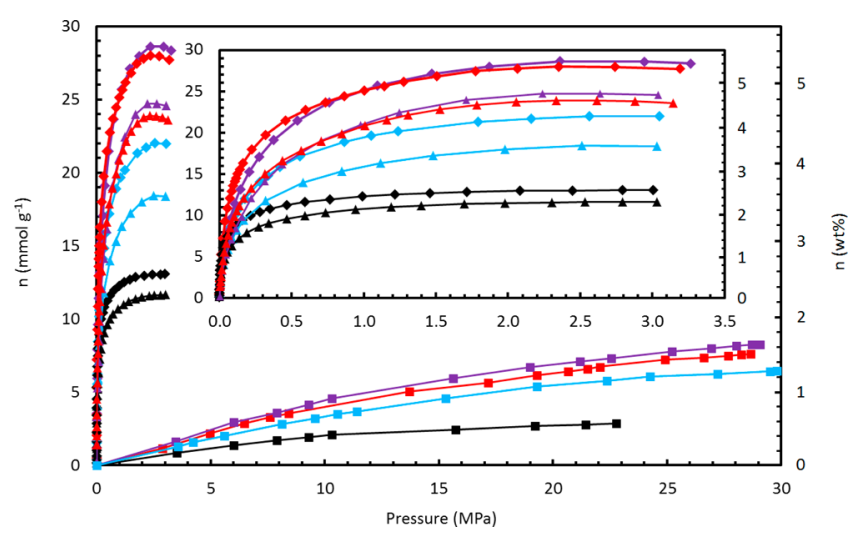

Figure 4. Equilibrium adsorption isotherms of hydrogen on MSC-30 (red), ZTC-2 (blue), ZTC-3 (purple), and CNS-201 (black) at $77 \mathrm{~K}$ (diamond), $87 \mathrm{~K}$ (triangle), and $298 \mathrm{~K}$ (square) between 0 and 30 $\mathrm{MPa}$ (inset shows detail between 0 and $3.5 \mathrm{MPa}$ ).

excess uptake in units of $\mathrm{mmol} \mathrm{g}^{-1}$, which is not linearly proportional to wt \% (shown on the right-hand axis). Hydrogen sorption was fully reversible in all materials studied after numerous cycles (see Supporting Information). Identical measurements were performed with an empty sample holder before each sample measurement to determine the relevant background adsorption by the apparatus for that specific routine. Instrument background was found to depend on sample bath temperature, number of steps, adsorption or desorption, and the particular sample holder used. The Gibbs surface excess maximum hydrogen capacities of the materials are summarized in Table 1. The highest measured was for ZTC-3: $28.6 \mathrm{mmol} \mathrm{g}^{-1}(5.5 \mathrm{wt} \%)$ at $2.4 \mathrm{MPa}$. Maximum uptake was higher in ZTC-3 than MSC-30 despite a gentler initial increase at low pressure.

3.3. Hydrogen Uptake at High Pressure. Equilibrium adsorption isotherms of $\mathrm{H}_{2}$ on ZTCs, MSC-30, and CNS-201 were measured at $298 \mathrm{~K}$ up to $30 \mathrm{MPa}$ and are shown in Figure 5 (the same data are shown in less detail in Figure 4).

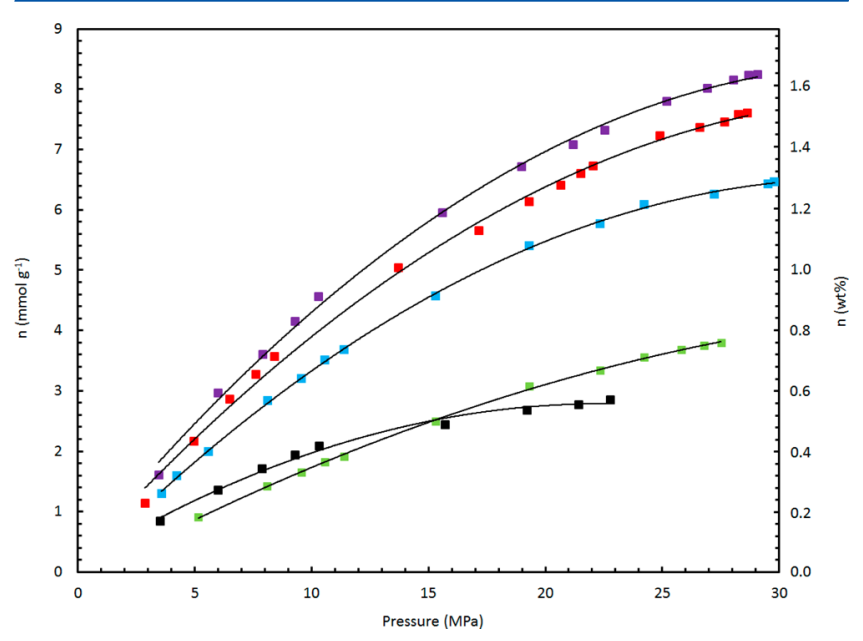

Figure 5. Equilibrium adsorption isotherms of $\mathrm{H}_{2}$ on MSC-30 (red), ZTC-1 (green), ZTC-2 (blue), ZTC-3 (purple), and CNS-201 (black) at $298 \mathrm{~K}$ between 0 and $30 \mathrm{MPa}$.

Hydrogen adsorption is reported as Gibbs's excess uptake in units of $\mathrm{mmol} \mathrm{g}^{-1}$ and identical measurements were performed with an empty sample holder before each sample measurement to determine the relevant background adsorption by the apparatus. Excess hydrogen capacities of the materials were calculated by extrapolation of the data to $30 \mathrm{MPa}$ and are summarized in Table 1. The highest measured was for ZTC-3: $8.3 \mathrm{mmol} \mathrm{g}^{-1}(1.6 \mathrm{wt} \%)$ at $30 \mathrm{MPa}$ and $298 \mathrm{~K}$.

Verification of the calibration of our high-pressure volumetric apparatus was by measurements of commercial materials MSC30 and CNS-201. However, comparison of standard materials to references was found to be reliable only in some instances. The superactivated carbon MSC-30, a material processed 
similarly to Anderson AX-21, is reported to have a BET surface area ranging from 2600 to $3400 \mathrm{~m}^{2} \mathrm{~g}^{-1}$. 3,5,8,11,16 This is not due simply to differences in the analysis of the $\mathrm{N}_{2}$ adsorption isotherms at $77 \mathrm{~K}$ but is also reflected in differences in hydrogen adsorption isotherms at temperatures from 77 to 298 $\mathrm{K}$, implying that different batches of MSC-30 have different properties. Hydrogen capacities of MSC-30 at $298 \mathrm{~K}$ range from 3 to $4 \mathrm{mmol} \mathrm{g}^{-1}(0.6-0.8 \mathrm{wt} \%)$ at $10 \mathrm{MPa}$; in this report, it was measured to be $3.9 \mathrm{mmol} \mathrm{g}^{-1}$, which is consistent with the upper end of this range. Hydrogen uptake in CNS-201 was $2.0 \mathrm{mmol} \mathrm{g}$ compared to a reference value of $2.1 \mathrm{mmol} \mathrm{g}^{-1.5}$

3.4. Isoexcess Enthalpy of Adsorption. Plots of adsorption enthalpy, $\Delta H_{\text {ads }}$, as a function of uptake, $n$, are shown in Figure 6. These calculations were performed by

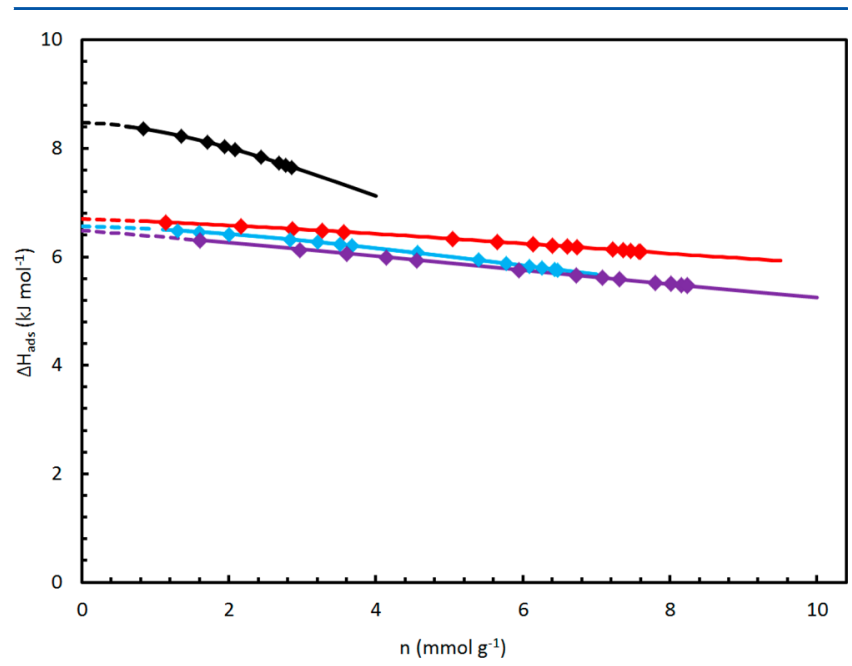

Figure 6. Isoexcess enthalpy of adsorption of hydrogen on MSC-30 (red), ZTC-2 (blue), ZTC-3 (purple), and CNS-201 (black) as a function of equilibrium excess uptake, calculated between 77 and 298 $\mathrm{K}$. Locations of data points from the $298 \mathrm{~K}$ isotherms are indicated by diamonds.

analyzing data from the entire range of temperature between 77 and $298 \mathrm{~K}$. Experimental excess adsorption data at temperature $T$ was treated by fitting with a model-independent virial-type thermal equation: ${ }^{29}$

$$
\ln \left(\frac{p}{n}\right)=\frac{1}{T} \sum_{i=0}^{3} a_{i} n^{i}+\sum_{i=0}^{3} b_{i} n^{i}
$$

In all cases, sensible least-squares fitting did not warrant terms higher than $n^{3}$. Enthalpy of adsorption was then calculated by using an analogous form of the Clausius-Clapeyron relation (known as the isosteric method):

$$
\Delta H_{\mathrm{ads}}(n)=-R\left(\frac{\partial \ln p}{\partial\left(\frac{1}{T}\right)}\right)=-R \sum_{i=0}^{3} a_{i} n^{i}
$$

Since measured Gibbs surface excess quantities were used rather than absolute uptake quantities (that need to be modeled), the $\Delta H_{\text {ads }}$ values must be regarded as "isoexcess heat of adsorption" and differ from absolute enthalpy values. $^{30,31}$ The "Henry's law value", $\Delta H_{0}$, was calculated by extrapolation of the adsorption enthalpy to zero pressure:

$$
\Delta H_{0}=\Delta H_{\text {ads }}(n=0)=-R a_{0}
$$

The Henry's law values for the materials studied are summarized in Table 1. The highest value reported is for CNS-201 which is known to have an exceptionally high binding energy for hydrogen. ${ }^{24}$ It decreases substantially as uptake increases, which is also reflected in the shape of the hydrogen uptake curves for CNS-201 at all temperatures. The adsorption enthalpy calculated for ZTCs and MSC-30 decreases only slightly and is relatively constant as uptake increases; it is thus responsible for the continued increase in uptake at $30 \mathrm{MPa}$ compared to CNS-201. Detail in the low uptake region was extrapolated and is shown as a dashed line on the curves in Figure 6.

\section{DISCUSSION}

The addition of sorbent material to a storage tank has two consequences: the volume available for gaseous storage is decreased (by the material's skeletal density), and the surface available for van der Waals interactions is increased (by the material's specific surface area). With enthalpy of adsorption in the range of 4-9 $\mathrm{kJ} \mathrm{mol}^{-1}$, as is observed for carbon materials, careful measurements of sample density and surface area are critical for characterizing sorption capacity and can be used together to readily predict material performance in the temperature and pressure conditions studied: $77-298 \mathrm{~K}$ and 0-30 MPa. Skeletal density is the only material specific variable required and therefore the most important variable in accurate determination of excess hydrogen uptake in adsorption measurements. Carbonaceous materials often have a similar skeletal density to graphite, $2.1-2.2 \mathrm{~g} \mathrm{~mL}^{-1} .5$ However, skeletal densities in ZTCs are significantly lower, $1.8 \mathrm{~g} \mathrm{~mL}^{-1}$. This indicates a less graphitic nature of ZTCs but is not easily explained since ZTCs are predominantly $\mathrm{sp}^{2}$ carbon. ${ }^{32,33}$ Distortions such as bond stretching or vacancy defects which could alter the ratio of $\mathrm{sp}^{2}$ to $\mathrm{sp}^{3}$ bonding of carbon atoms would have to be large to account for this difference. However, the fractions of $\mathrm{sp}^{2}$ and $\mathrm{sp}^{3}$ bonding were found to be similar through auxiliary measurements by X-ray photoelectron spectroscopy (XPS), electron energy-loss spectroscopy (EELS), and solid-state ${ }^{13} \mathrm{C}$ nuclear magnetic resonance (NMR), shown in the Supporting Information. Perhaps differences in hydrogen edge terminations between ZTCs and other carbons may be large enough to account for the reduced skeletal density.

Hydrogen uptake at 77 and $298 \mathrm{~K}$ is generally proportional to surface area in the materials studied, as shown in Figure 7. The relationship for ZTCs at $77 \mathrm{~K}$ is $9 \mathrm{mmol} \mathrm{g}^{-1}$ (1.8 wt \%) Gibbs excess surface maximum hydrogen capacity per $1000 \mathrm{~m}^{2}$ $\mathrm{g}^{-1}$ BET surface area, the same as for other carbonaceous materials. This corresponds to 5.4 molecules of $\mathrm{H}_{2}$ per $\mathrm{nm}^{2}$ of BET surface area. The relationship for ZTCs at $30 \mathrm{MPa}$ and $298 \mathrm{~K}$ is $2.3 \mathrm{mmol} \mathrm{g}^{-1}$ (0.46 wt \%) excess hydrogen uptake per $1000 \mathrm{~m}^{2} \mathrm{~g}^{-1}$ BET surface area, the same as for other carbonaceous materials in this study. Importantly, this result is contrary to a previous result ${ }^{16}$ which reports higher uptake in ZTCs at $303 \mathrm{~K}: 2.8 \mathrm{mmol} \mathrm{g}^{-1}$ (0.55 wt \%) excess hydrogen uptake per $1000 \mathrm{~m}^{2} \mathrm{~g}^{-1}$ BET surface area in "P7(2)-H", compared to $2.0 \mathrm{mmol} \mathrm{g}^{-1}(0.41 \mathrm{wt} \%)$ per $1000 \mathrm{~m}^{2} \mathrm{~g}^{-1}$ in MSC-30. In this previous report, a $100 \%$ increase in uptake was measured for ZTCs compared to MSC-30, and it could not be explained by surface area.

While ZTCs measured in the present study show increased uptake compared to MSC-30, this was consistent with their larger specific surface area. These relationships are critically 


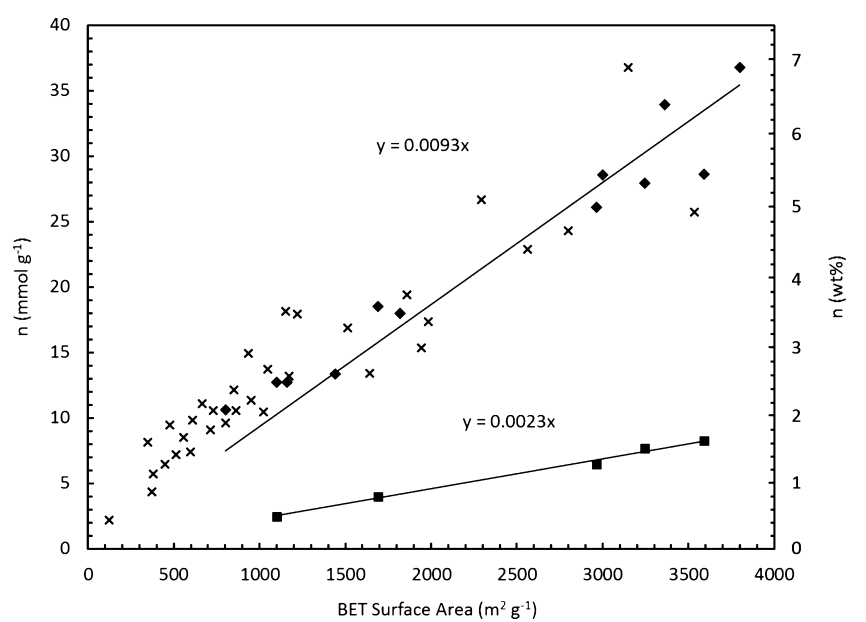

Figure 7. Equilibrium excess adsorption uptake of hydrogen as a function of BET surface area at $77 \mathrm{~K}$ (Gibbs excess surface maximum capacity: diamond) and $298 \mathrm{~K}$ (at $30 \mathrm{MPa}$ : square). An $\times$ indicates a reported value from the literature at $77 \mathrm{~K}^{37}$

dependent on the accurate and consistent determination of specific surface area of the sorbent material and the assumptions inherent to BET theory. The known shortcomings of this method for microporous materials are thought to be approximately equal in the materials studied. However, extreme care must still be taken in analysis of the nitrogen isotherms at $77 \mathrm{~K}$; assumption of a standard pressure range over which to fit the BET equation is not appropriate. The region from low pressure up to the knee of the isotherm ("point B" for a type II isotherm) must be included as this pressure range is different for each material. For MSC-30, the calculation is especially sensitive to the range chosen because the knee is rounded and there are two nearly linear regions in the isotherm (type IV like character). Even for classic type II isotherms, BET surface area is often miscalculated: in "CB850h", a ZTC which was reported to have a maximum excess hydrogen capacity of $8.33 \mathrm{wt} \%$ at 77 $\mathrm{K}, \mathrm{BET}$ surface area is calculated to be $3150 \mathrm{~m}^{2} \mathrm{~g}^{-1} \cdot{ }^{34}$ This figure would represent an extreme outlier on a plot of hydrogen capacity at $77 \mathrm{~K}$ as a function of surface area; however, our analysis of the reported $\mathrm{N}_{2}$ isotherm data gives a BET surface area of $3800 \mathrm{~m}^{2} \mathrm{~g}^{-1}$, much closer to the expected value for such a high capacity sorbent. Similarly, "P7(2)-H" was reported to have a BET surface area of $3800 \mathrm{~m}^{2} \mathrm{~g}^{-1}$ (while our analysis yields a value of $\left.3538 \pm 50 \mathrm{~m}^{2} \mathrm{~g}^{-1}\right) .{ }^{16}$ Another method of ranking similar sorbents of the same material class is by comparing the nitrogen uptake capacity at $77 \mathrm{~K}$ and an intermediate pressure, say $P / P_{0}=0.5$. This analysis also shows "CB850h" to be among the highest performance sorbent materials and explains the large excess hydrogen capacity at 77 K. ZTC-3 was found to be nearly identical to "P7(2)-H" in this comparison and explains the similar surface area when a consistent calculation method is used.

The similarity of isoexcess enthalpies of adsorption between ZTCs and MSC-30 in Figure 6 implies that there are no significant differences in the dispersion forces responsible for hydrogen physisorption. The high-pressure data at $298 \mathrm{~K}$ allow the unique contribution of high-temperature data to the calculation of isoexcess enthalpy of adsorption. However, dispersion forces are known to have a significant temperature dependence. $^{31,35}$ For instance, the heat of adsorption of hydrogen on MOF-5 is reported to increase by up to $\sim 1 \mathrm{~kJ}$ $\mathrm{mol}^{-1}$ between cryogenic and room temperatures. ${ }^{31}$ Therefore, the values given in Table 1 are to be understood as averages over the whole temperature range for the given material. Indeed, when only $77-87 \mathrm{~K}$ data were fitted for calculation of the isoexcess enthalpy of adsorption, in all cases the value was decreased by up to $0.7 \mathrm{~kJ} \mathrm{~mol}^{-1}$ (in the range measured).

The hydrogen uptake character in ZTCs at $77 \mathrm{~K}$, especially ZTC-3, is slightly different from MSC-30 because the uptake is lower between 0 and 1.0 MPa but exceeds MSC-30 between 1.0 and 2.4 MPa. For effective hydrogen delivery by a sorbent material between two finite pressures, $P_{\mathrm{f}}-P_{\mathrm{i}}$, it is favorable to have an excess uptake slope that is gradual below $P_{\mathrm{f}}$ and steep in the cycled region of uptake/delivery; the quantity of hydrogen delivered is the difference between the amount in the initial (fully charged) state at $P_{\mathrm{i}}$ and the final (considered "empty") state at $P_{\mathrm{f}}$. For delivery to a fuel cell, $P_{\mathrm{f}}$ is often taken to be $0.3 \mathrm{MPa}{ }^{36}$ Therefore, ZTCs used for this purpose at $77 \mathrm{~K}$ exhibit higher hydrogen delivery than MSC-30 by $15 \%$ when cycled between 0.3 and $2.4 \mathrm{MPa}$.

\section{CONCLUSIONS}

Equilibrium hydrogen uptake capacities of ZTCs at room temperature are among the highest of known physisorbent materials due to their large specific surface area. Hydrogen capacity in ZTCs is approximately proportional to surface area at $298 \mathrm{~K}$ between 0 and $30 \mathrm{MPa}$, as is consistent with a large variety of carbonaceous materials, including activated carbons, carbon fibers, graphite, aerogels, and nanotubes. That is, a "Chahine's rule" type of trend is observed at room temperature and fixed pressure for carbon-based materials. For example, this trend is found to be $2.3 \mathrm{mmol} \mathrm{g}^{-1}(0.46 \mathrm{wt} \%)$ excess hydrogen uptake per $1000 \mathrm{~m}^{2} \mathrm{~g}^{-1} \mathrm{BET}$ surface area at $30 \mathrm{MPa}$. ZTCs were found to have an isoexcess enthalpy of adsorption comparable to MSC-30 when measured between 77 and $298 \mathrm{~K}$ : $6.5 \mathrm{~kJ} \mathrm{~mol}^{-1}$ in the Henry's law limit. This implies that there are no significant differences in the dispersion forces responsible for hydrogen physisorption in ZTCs compared to MSC-30. Unlike other carbons, ZTCs were measured to have significantly lower skeletal density; this has the effect of increasing calculated uptake and straightening the uptake curve with increasing pressure. This is beneficial for gravimetric hydrogen delivery by ZTCs during cycling between two finite pressures in an engineering application, especially at $77 \mathrm{~K}$.

\section{ASSOCIATED CONTENT}

\section{S Supporting Information}

Additional materials characterization and data analysis were performed to show reproducibility of the results, validate the templated structure of ZTCs, further analyze the micropore character of MSC-30 and ZTCs, and probe differences in chemical bonding between MSC-30 and ZTCs that could clarify their significant difference in skeletal density. This material is available free of charge via the Internet at http:// pubs.acs.org.

\section{AUTHOR INFORMATION}

\section{Corresponding Author}

*E-mail: nstadie@caltech.edu.

\section{Notes}

The authors declare no competing financial interest. 


\section{ACKNOWLEDGMENTS}

This work was supported as part of EFree, an Energy Frontier Research Center funded by the U.S. Department of Energy, Office of Science, Office of Basic Energy Sciences under Award Number DE-SG0001057.

\section{REFERENCES}

(1) Schlapbach, L.; Züttel, A. Nature 2001, 414, 353-358.

(2) Zubizarreta, L.; Gomez, E. I.; Arenillas, A.; Ania, C. O.; Parra, J. B.; Pis, J. J. Adsorption 2008, 14, 557-566.

(3) Poirier, E.; Chahine, R.; Bose, T. K. Int. J. Hydrogen Energy 2001, 26, 831-835.

(4) Panella, B.; Hirscher, M.; Roth, S. Carbon 2005, 43, 2209-2214.

(5) Richard, M. A.; Cossement, D.; Chandonia, P. A.; Chahine, R.; Mori, D.; Hirose, K. AIChE J. 2009, 55 (11), 2985-2996.

(6) Purewal, J. J.; Keith, J. B.; Ahn, C. C.; Fultz, B.; Brown, C. M.; Tyagi, M. Phys. Rev. B 2009, 79, 054305.

(7) Ströbel, R.; Garche, J.; Moseley, P. T.; Jörissen, L.; Wolf, G. J. Power Sources 2006, 159 (2), 781-801.

(8) Li, Y.; Yang, R. T. J. Phys. Chem. C 2007, 111, 11086-11094.

(9) Sculley, J.; Yuan, D. Q.; Zhou, H. C. Energy Environ. Sci. 2011, 4, 2721-2735.

(10) Campesi, R.; Cuevas, F.; Latroche, M.; Hirscher, M. Phys. Chem. Chem. Phys. 2010, 12, 10457-10459.

(11) Stadie, N. P.; Purewal, J. J.; Ahn, C. C.; Fultz, B. Langmuir 2010, 26, 15481-15485

(12) Chung, T. C. M.; Jeong, Y.; Chen, Q.; Kleinhammes, A.; Wu, Y. J. Am. Chem. Soc. 2008, 130 (21), 6668-6669.

(13) Jin, Z.; Sun, Z.; Simpson, L. J.; O’Neill, K. J.; Parilla, P. A.; Li, Y.; Stadie, N. P.; Ahn, C. C.; Kittrell, C.; Tour, J. M. J. Am. Chem. Soc. 2010, 132, 15246-15251.

(14) Kyotani, T. Carbon 2000, 38, 269-286.

(15) Kyotani, T.; Nagai, T.; Inoue, S.; Tomita, A. Chem. Mater. 1997, 9, 609-615.

(16) Nishihara, H.; Hou, P. X.; Li, L. X.; Ito, M.; Uchiyama, M.; Kaburagi, T.; Ikura, A.; Katamura, J.; Kawarada, T.; Mizuuchi, K.; Kyotani, T. J. Phys. Chem. C 2009, 113, 3189-3196.

(17) de la Casa-Lillo, M. A.; Lamari-Darkrim, F.; Cazorla-Amorós, D.; Linares-Solano, A. J. Phys. Chem. B 2002, 106, 10930-10934.

(18) Liu, B.; Shioyama, H.; Akita, T.; Xu, Q. J. Am. Chem. Soc. 2008, 130, 5390-5391.

(19) Liu, B.; Shioyama, H.; Jiang, H.; Zhang, X.; Xu, Q. Carbon 2010, $48,456-463$.

(20) Jiang, H. L.; Liu, B.; Lan, Y. Q.; Kuratani, K.; Akita, T.; Shioyama, H.; Zong, F.; Xu, Q. J. Am. Chem. Soc. 2011, 133, 1185411857.

(21) Gregg, S. J.; Sing, K. S. W. Adsorption, Surface Area and Porosity, 2nd ed.; Academic Press: New York, 1982; pp 49-56.

(22) Tarazona, P.; Marconi, U. M. B.; Evans, R. Mol. Phys. 1987, 60, 573-595.

(23) Bowman, R. C., Jr.; Luo, C. H.; Ahn, C. C.; Witham, C. K.; Fultz, B. J. Alloys Compd. 1995, 217, 185-192.

(24) Purewal, J. J.; Kabbour, H.; Vajo, J. J.; Ahn, C. C.; Fultz, B. Nanotechnology 2009, 20, 1-6.

(25) Lemmon, E. W.; Huber, M. L.; McLinden, M. O. NIST Standard Reference Database 23: Reference Fluid Thermodynamic and Transport Properties - REFPROP 2007, version 8.0.

(26) Kiyobayashi, T.; Takeshita, H. T.; Tanaka, H.; Takeichi, N.; Züttel, A.; Schlapbach, L.; Kuriyama, N. J. Alloys Compd. 2002, 330332, 666-669.

(27) Blach, T. P.; Gray, E. M. J. Alloys Compd. 2007, 446-447, 692697.

(28) Langford, J. I.; Wilson, J. C. J. Appl. Crystallogr. 1978, 11, 102113.

(29) Czepirski, L.; Jagiello, J. Chem. Eng. Sci. 1989, 44, 797-801.

(30) Sircar, S. Ind. Eng. Chem. Res. 1999, 38, 3670-3682.

(31) Mertens, F. O. Surf. Sci. 2009, 603, 1979-1984.
(32) Ma, Z.; Kyotani, T.; Liu, Z.; Terasaki, O.; Tomita, A. Chem. Mater. 2001, 13, 4413-4415.

(33) Yang, Y.; Brown, C. M.; Zhao, C.; Chaffee, A. L.; Burke, N.; Zhao, D.; Webley, P. A.; Schalch, J.; Simmons, J. M.; Liu, Y.; Her, J. H.; Buckley, C. E.; Sheppard, D. A. Carbon 2011, 49, 1305-1317.

(34) Yang, Z.; Xia, Y.; Mokaya, R. J. Am. Chem. Soc. 2007, 129, $1673-1679$.

(35) Obrecht, J. M.; Wild, R. J.; Antezza, M.; Pitaevskii, L. P.; Stringari, S.; Cornell, E. A. Phys. Rev. Lett. 2007, 98, 063201.

(36) DOE Targets for Onboard Hydrogen Storage Systems for LightDuty Vehicles, revision 4.0, http://www1.eere.energy.gov/ hydrogenandfuelcells/storage/pdfs/targets_onboard_hydro_storage. pdf.

(37) Hirscher, M.; Panella, B.; Schmitz, B. Microporous Mesoporous Mater. 2010, 129, 335-339. 